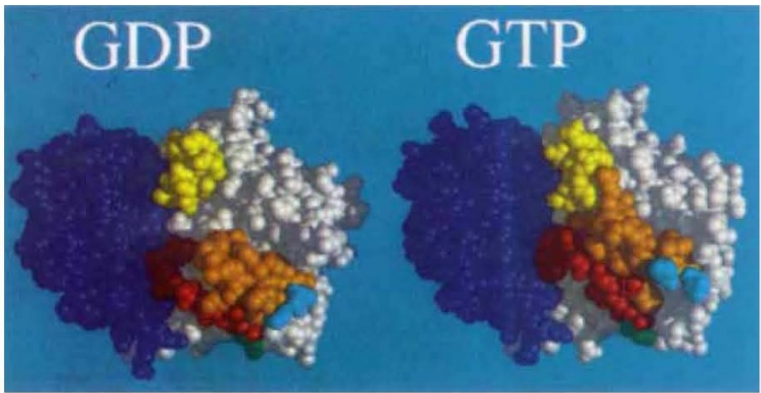

FIG. 2 Space-filling models showing the switch regions (red, orange, cyan, yellow) of $\alpha_{\mathrm{t}}$. GDP and $\alpha_{\mathrm{t}}$. GTP, as described in the text. Bound guanine nucleotide (not visible) is located in a binding pocket between the Ras-like core domain (white) and the $\alpha$-helical domain ${ }^{2}$ (dark blue) that stimulates its GTPase activity $^{16}$. (Coordinates of the two structures ${ }^{1.2}$ provided by Paul Sigler.)

(refs 8,9), apparently by preventing GTPinduced conformational change in the $\alpha 2$ helix of switch II. Moreover, the $\beta$-chain of a $\mathrm{G}_{0}$ heterotrimer can be crosslinked to a cysteine in the switch II region of $\alpha_{\mathrm{o}}$ (ref. $10)$ and genetic analysis in Saccharomyces cerevisiae suggests that the $\alpha-\beta \gamma$ interaction involves a $G_{\alpha}$ residue that is cognate to the green residue (Q184 of $\alpha_{\mathrm{t}}$ ) in Fig. 2 . near both switch I and switch II. As an additional potential $\mathrm{G}_{\beta \gamma}$ interaction site, Lambright et al. point to the shallow groove in $\alpha_{\mathrm{t}} \cdot$ GDP, just above switch II, which is filled in by part of the diagonal hump (mostly switch II) in $\alpha_{\mathrm{t}}$ GTP.

A second consequence of the conformation induced by the $\gamma$-phosphate is that it converts $\mathrm{G}_{\alpha}$ into a protein that can activate effectors directly; examples include activation of adenylyl cyclase by $\alpha_{\mathrm{s}}$ and of retinal cyclic GMP phosphodiesterase by $\mathrm{G}_{\mathrm{t} \alpha}$. Although effectors must interact, at least in part, with conformationally changed surfaces of $\mathbf{G}_{\alpha}$, site-directed $\alpha$, mutations $^{11,12}$ and biochemical effects of $\mathrm{G}_{\mathrm{t} \alpha}$ peptides ${ }^{13}$ identify effectorinteracting residues in these two $G_{\alpha}$ proteins which are located for the most part in surface regions unaffected by conformational change; these regions (not coloured) are located near the top right edge of the side of $\mathrm{G}_{\alpha}$ depicted in Fig. 2. The switch regions do contain at least one putative effector-contact region, however; in $\alpha_{s}$, this short stretch of sequence ${ }^{11,12}$ corresponds to residues (cyan in Fig. 2) in the turn that follows the $\alpha 2$ helix of switch II in $\mathrm{G}_{\mathrm{t} \alpha}$.

The proximity of identified effectorinteracting residues (cyan) to residues that interact with $\mathrm{G}_{\beta \gamma}$ (switch II and the green residue in Fig. 2) makes it likely that the $\mathrm{G}_{\beta \gamma^{-}}$and effector-interacting surfaces of $\mathrm{G}_{\alpha}$ overlap significantly within the small surface area occupied by the switch regions. The overlap means that $\mathrm{G}_{\alpha}$ cannot interact with an effector until it divests itself of the $\beta \gamma$ subunits.

The two $\mathrm{G}_{\mathrm{t} \alpha}$ structures do not, however, shed much light on a third protein- protein association, one essential for signal transmission but dependent on the absence of the $\gamma$-phosphate - that is, binding of both $\mathrm{G}_{\alpha}$ and $\mathrm{G}_{\beta \gamma}$ to the receptor (Fig. 1). Physiologically, $\gamma$ phosphate-induced reversal of this association is important because it allows a single receptor molecule to activate additional G-protein molecules, thus amplifying the extracellular signal. The reversal may be explained, at least in part, as a consequence of GTP-induced dissociation of the $\alpha$ from the $\beta \gamma$ subunits, in that $\mathrm{G}_{\beta \gamma}$ appears to be required for effective interaction of the receptor with $\mathrm{G}_{\alpha}$ (ref. 14; Fig. 1). Nonetheless, it is striking that most of the $\mathrm{G}_{\alpha}$ surfaces thought $^{2,15}$ to interact with receptors are on the side of the protein opposite the surface (Fig. 2) that changes conformation in a GTP-dependent manner. A possible exception is the protein's extreme carboxy terminus, which was found (in one of three $\alpha_{\mathrm{t}} \cdot \mathrm{GTP}-\gamma \mathrm{S}$ protomers ${ }^{2}$ ) juxtaposed to the turn containing the effectorinteracting (cyan) residues in Fig. 2.

The receptor-G-protein puzzle sets a third and yet more formidable challenge for doughty G-protein crystallographers - show us a freeze-frame picture of the 'empty' state of $\mathrm{G}_{\alpha}$ (the question-mark in Fig. 1), the mysterious conformation, stabilized by activated receptor and $\mathrm{G}_{\beta \gamma}$, that serves as a transition state in the GTP/GDP exchange reaction. Now that we know what a difference a $\gamma$-phosphate makes, we want to know how it gets there.

Henry R. Bourne is in the Departments of Pharmacology and Medicine, University of California, San Francisco, California 94143, USA.

1. Lambilight, D. G., Noel, J. P., Hamm, H. E. \& Sigler, P. B. Nature 369. 621-628 (1994)

2. Noel, J. P. Hamm, H. E \& Sigler. P. B. Nature 366 $654-663$ (1993)

3. Bourne, H. R. Nature 366, 628-629 (1993).

4. Stryer. L. A. Rev. Neurosci. 9.87-119 (1986)

5. Kaziro, Y., Itoh, H., Kozasa, T., Nakafuku, M. \& Satoh, T. A. Rev. Biochem. 60, $349-400$ (1991)

6. Bourne, H. R. Sanders, D. A. \& McCormick. F. Nature 348, 125-132 (1990)

7. Bourne, H. R., Sanders, D. A. \& McCormick, F. Nature 349, 117-127 (1991)

349, 117-127 (1991).
Miller. R. T., Masters, S. B., Sullivan, K. A., Beiderman B. \& Bourne, H. R. Nature 334, 712-715 (1988)

9. Lee, E., Taussig, R. \& Gilman, A. G.J. biol. Chem. 267 1212-1218 (1992)

10. Thomas, T. C. Schmidt, C. J. \& Neer, E. J. Proc. natn Acad. Sci. U.S.A. 90, 10295-10299(1993)

1. Berlot, C. H. \& Bourne, H. R Cell 68, 911-922 (1992)

11. Berlot, C. H. \& Bourne, H. R. Cell68, 911-922(1992) 16226 16231 (1991)

13. Rarick, H. M., Artemyev, N. O.\&Hamm, H. E. Science 256. 1031-1033 (1992)

14. Fung, B. K.-K.J. biol. Chem. 258, 10495-10502 (1983).

15. Conklin, B. R. \& Bourne, H. R. Cell 73, 631-641 (1993)

16. Markby, D. W., Onrust, R. \& Bourne. H. R. Science 262 1895-1901 (1993).

\section{The long view}

THE human eye cannot hold an image for long. Film and television, which repeatedly present a new image before the old one has faded, give the illusion of continuous motion. Daedalus argues that this persistence of vision is not merely a form of retinal inertia. If it were, a bright image should persist for longer, as it does in a television camera. In fact, the eye's image-fusion rate is about $50 \mathrm{~Hz}$ in bright light, but only $10 \mathrm{~Hz}$ in dim lighthence the advantage of a dimly-lit cinema. Daedalus reckons that the rate is set by the visual pathways. He points out the curious fact that the human imagefusion frequency falls with rising hydrostatic pressure.

At first he began to dream up an underwater cinema for deep-sea divers, in which even jerky old films with their low frame-rate would appear smooth and continuous. But he then recalled that pressure affects many biochemical processes by altering the permeability of cell membranes. Thus it can slow the swimming of Paramecium by blocking the entry of calcium ions into its cilia.

Many drugs can also work this trick. They can bind to a specific ion and alter its diffusion rate far more dramatically than any feasible hydrostatic pressure. Daedalus suspects that drugs such as mescaline and LSD act like this. By disrupting the time constants of the user's visual pathways, they distort his visual impressions and sabotage his time sense. So DREADCO's biochemists are now modifying these drugs to fine-tune this action. Their goal is a drug that has no psychedelic effects, but greatly extends the persistence of vision.

DREADCO's 'Slowview' may merely induce a drugged nightmare of lagging and persistent images. But Daedalus hopes that, by slowing the whole time. dependent process of visual interpretation, it will in effect convert the eye into a time-lapse camera. A new world of leisurely movement will spring to life. The user of Slowview will retain his normal internal clock and reaction time, but his effective 'visual present' will extend to many seconds. He will appreciate optical changes too gradual for the rest of us to notice: the slow convolutions of a cloudscape, the opening of flowers, the changing shadow patterns of a forest, the growth of crystals and even that cliché of ultimate boredom, the drying of paint. With the aid of Slowview, a lantern-slide lecture will become a true movie, botany will become a fast-moving subject and sluggish reptiles such as skinks will appear as frisky and vivacious to us as they doubtless do to each other.

David Jones 